\title{
Research on the Cultural Connotation of Yangge in Northern Shaanxi Hui Gao ${ }^{1, a}$ \\ ${ }^{1}$ Xi'an Fanyi University, Shaanxi Xi'an, China, 710105 \\ aemail,
}

\author{
Keywords: Northern Shaanxi Yangge; Culture; Connotation
}

\begin{abstract}
At present, the traditional regional dance system continues to develop and enrich, and gradually accepted and appreciated by the public. Among them, the northern Shaanxi Yangge has developed and learned the traditional Yangge with unique unique local characteristics and cultural attributes, and has become a unique dance. In the northern Shaanxi Yangge, through different styles and movements reflect the different cultural characteristics, its representative cultural characteristics, inherited the oldest and most traditional traditional cultural attributes, from the Yangge's artistic style and cultural heritage A rich cultural connotation, the entire dance culture heritage is of great significance. Based on this, this paper studies the cultural connotation of yangge in northern Shaanxi in order to promote the cultural development of yangge in northern Shaanxi and promote the development of yangge in northern Shaanxi.
\end{abstract}

\section{Northern Shaanxi Yangge}

Northern Shaanxi Yangge. Northern Shaanxi Yangge is a popular dance that is popular in northern Shaanxi. The contents and forms of the Yangge are diversified and are extensive and representative in the northern Shaanxi plateau region. Various forms of Shaanxi Yangge cultural connotation is the yangko art culture and performance of the internal spirit of the general term. It includes the performance of the Yangge performance, artistic expression. In the cultural connotation of Yangge, it is included in the cultural connotations of the expression of emotion and the inner spirit of the Yangge itself. There are two major types of strict species in northern Shaanxi, including the "Yangge Song" and "Kick Field", different Yangge genre in different yangko style, which has a corresponding cultural attributes, but from the macro level analysis, Cultural connotation is the entire northern Shaanxi Yangge both inside and outside the performance of the artistic form and heritage of the comprehensive summary of the culture.

The Cultural Characteristics of the Yangge in Northern Shaanxi. As the origin of northern Shaanxi Yangge earlier, and a wide range of branches, making the northern Shaanxi Yangge culture is more abundant. According to the development and evolution of the Yangge Yangge, the culture of the northern Shaanxi Yangge mainly has two characteristics.

Guidance. The so-called guidance refers to the culture can be a direct impact on traditional culture factors, the performance of the Yangge and rhythm changes have a role, and directly control the performance of Yangge. For example, in northern Shaanxi Yangge performance, usually in the first month of fifteen performances, with a strong festive culture of the property, the traditional festivals in the culture, with different prayers, sacrifices and even the harvest festival culture on the specific The performance of the form has a different effect. For example, the prayer and worship of the Yangge performance for the magnificent but more solemn, harvest festival is to Yangko reflect the joy and entertainment of cultural attributes.

Content. Northern Shaanxi Yangge has rich emotional expression and artistic connotation, which are displayed through its culture, in other words, the culture of northern Shaanxi Yangge is the potential expression of dance emotion connotation, which has the hidden power of dance content. Culture through the Yangge external action and the entire performance of the grasp, and then produce a different Yangge action that some emotional expression, as well as changes in physical changes in the body, which constitute the cultural substantive content. Such as the Northern Shaanxi Yangge is mainly used to show the old "social fire" cheerful and hope for the future days. In the performance of the Yangge, pay attention to the red and colorful dress, while the Yangge will play 
with a fan, used to show a colorful festival culture, the specific holiday situation, Yangge performers dance more cheerful, and the entire dance action with a flexible twist, a substantial twist, and then reflect the joy of the holiday.

\section{The Connotation of Yangge Culture}

Folk Culture. Sacrifice culture. Northern Shaanxi Yangge use the traditional Yangge dance performance, showing a strong ritual charm. Most of the dance performances in northern Shaanxi Yangge are lively and the use of rich and flexible dance steps to form a uniform dance performance, showing a magnificent and bustling dance momentum. Modern dance yangge performances, most of the actors will use three steps, that is, three steps but not landing. The actress is holding a fan, wagging the body to perform, in the dance action, in the specific action, the use of a large number of jump and kicking and walking and cross dance, in fact, the witch culture inheritance and development. At the same time when the fire and the male and female actors use a lot of bending, take off, showing a heroic dance. In addition, the northern Shaanxi Yangge retained the ancient wizard technology, the torsion and excitement of the action and the obvious take-off and cross the action.

Regional culture in northern Shaanxi. Many of the activities of the Northern Shaanxi Yangge, in the retention of the basic waggere outside, the use of three bends, arm circle and other specific actions and draw the agricultural, the farmers farming action essence, showing a smooth beauty. Performance art charm is mostly manifested in the cooperation between men and women Yangge performances, in the "trouble fire" in the male and female dance performances, the actor around the shaking his head around, and repeated rounded action, to the People to shock and lively visual experience, and then arm up the actress, actress dancers in the hands of the fan, the formation of uniform and magnificent and hustle and bustle of the form. The whole yangge performance through mutual cooperation and uniform action, twisted double gourd, jujube chaos flowering, ten lights, twelve lantern lights sets of lights, Eight Immortals and other dance graphics graphics, reflecting the northern Shaanxi region rough and heroic culture characteristic. At the same time the northern Shaanxi Yangge began to young development, combined with the regional cultural characteristics, the actress a substantial rotation of the body, the entire dance performance has a strong power, but at the same time there are smart beauty. The use of these big moves and more life of the dance, emotional expression and stage show, but it is precisely this performance reflects the sense of power of farming culture, but also the use of unexpected beauty to give people fresh and shock in the visual.

Dance Culture. Dance art. The dance of northern Shaanxi Yangge presents intuitionistic, the whole dance tension is enough, the northern Shaanxi Yangge through the internal emotional control, making the external action rhythm corresponding changes. Northern Shaanxi Yangge in a large number of different occasions and different festivals under the emotional expression of the adjustment, specific to each action and details of the changes, the formation of "internally and exquisite art beauty", such as ritual activities, in order to make the whole Yangko dance can be distinguished from the traditional festival of Yangge performances, to dance the regularity and dignity as a starting point, so that every action of the dance break through the constraints and limbs of the double obstacles, showing a bold and strong and solemn magnificent dance charm. In the cheerful festival of Yangge performances, the use of a large number of props as a supporting tool to improve the performance of the tension and dance show force. Which is obvious butterfly fan, in the fire when the fire, in order to achieve the "first month fifteen" festive atmosphere, the use of a large number of color dinette, the use of color fans of the alternate use of these dancers dancing fast, and generally Is open, used to express the Taihang Mountains farmers happy mood and cheerful situation, that is, a beauty of the show, but also a symbol.

Musical instruments. The artistic characteristics of the instruments of the Northern Shaanxi Yangge are mainly the use of the copper suona, drums and piano in northern Shaanxi. The number of instruments used in the form of Shanbei Yangge is also relatively simple. In the embodiment of various scenes, the use of the instruments of the Northern Shaanxi Yangge is generally used to 
maintain a variety of musical instruments at the same time to use the suona to create a scene, with the umbrella of the lyrics, in this vocal fusion of the use of circumstances, grasp the use of the suona tone and the use of time To ensure the opening of Yangge momentum. In the dance performances, the use of a variety of musical instruments blend, enrich the contents of the entire Yangge performances, to express the scene of the three-dimensional show. In the northern Shaanxi Yangge, the use of more frequent most of the loud and can extend the scope of the entire performance, the copper suona as a representative of the northern Shaanxi musical instruments, the sound low, bright and strong, lingering long lasting, with a very unique of the artistic effect, can directly reflect the bold in northern Shaanxi. And in the control of the suona tone, can be very good with the festival range of integration, reflecting the sad or cheerful and even solemn. Northern Shaanxi Yangge use of the characteristics of northern Shaanxi bronze suona, gongs and drums, reflecting the strong northern Shaanxi style, and make up the Yangge in the show festive festivals on the limitations, so that the joy of the holiday atmosphere from the auditory arrival of people's heart.

\section{The Cultural Heritage of Northern Shaanxi Yangge}

It Is the Inheritance of the Traditional Culture. In the development of the Yangge Yangge, the development of its culture and art fully emphasized the original ecological development form of the northern yangge in northern Shaanxi, and emphasized the regularity and the regularity of the origin and action of the Yangge. Therefore, the strengthening of the northern Shaanxi Yangge cultural connotation of the inheritance, is the northern Shaanxi Yangge the development of the primary state, is the essence of inheritance in northern Shaanxi Yangge dance. In the action, to retain a large number of traditional Yangge characteristics of action, including "chest fan", "walking step" and other actions, grasp the Yangge dance "twist" and "twist" action law, clearly portrayed The performance of the dance, making the northern Shaanxi Yangge art development line is not deviated and fuzzy. At the same time the Northern Shaanxi Yangge has the nature of the whole people, that is, the performance of the northern Shaanxi Yangge is the traditional culture of the inheritance and even the development of traditional culture, and therefore out of the mentality of inheritance, Shaanxi Northern Yangko staff to participate in the span of more than other activities for the regional masses, the participants of the northern Shaanxi Yangge basically covers the whole region family, many young generation and even infants and young children will be actively promoted by the older generation. And Yangge as an important part of the festival activities, in order to show the tension and attributes of dance, its composition of the men and women, these people perform on the Yangge, in fact, dance system and dance performance of the inheritance, it is the Yangge this A traditional culture of a heritage of the embodiment, fully embodies the impact of festivals, making the dance culture to be inherited and developed.

It Is the Development of Dance Culture. Northern Shaanxi Yangge is a branch of Yangge, which in the historical development, based on the popular period of farming performance on the root, coupled with the absorption of different ages of songs and dances, including regional folk songs and modern dance system under the form of dance, the formation of Now the independent form of Yangge, the regional dance culture for the effective development embodied in two aspects, on the one hand the performance of northern Shaanxi Yangge was originally set witch culture and the local farming form in one, by the local dance music elements The influence of the evolution and development so far, the formation of a unique Yangge form, but in contrast with other places Yangge, the history of northern Shaanxi Yangge inheritance strong, its Yangge in the temple, color doors, nine performances, Retains a large part of the ancient witch worship of the action, while the northern Suide region also retained the "God will Yangge", has been developed so far, in fact, is a heritage of ancient culture of worship. On the other hand, because of the new dance and the absorption ability of the song body in the northern Shaanxi, the development of the process, based on the Yangge twisted pendulum mode, the formation of a variety of dance movements, the region's film music and dance Absorption and development, to a certain extent, it is the development of traditional dance. 


\section{Conclusion}

The study of the cultural connotation of the northern Shaanxi Yangge is an important part of the study of our country's Yangge, and it is also an important content to study the local characteristics of song and dance culture, which can effectively promote the development and innovation of the Yangge Yangge. The research has theoretical and practical significance. The development of art culture in northern Shaanxi Yangge is of great significance to the inheritance of regional dance art, and it has obvious significance for the development of folk traditional dance.

\section{Acknowledgements}

Fund Project: Shaanxi Provincial Social Science and Art Project 2016 Annual Project, Project No. sy2016031

\section{References}

[1] Zhang Jin-jin. Study on the Style and Cultural Value of Yangge Yangge [J] .New West (Theoretical Edition), 2016, (11): 40-41.

[2]Journal of Beijing Dance Academy, 2016 (01): 41-45 (in Chinese) [J]. Journal of Beijing Dance Academy, 2016 (01): 41-45.

[3] Xue Xiaoxu. On the northern Shaanxi Yangge cultural and ecological development of the system [J]. Yellow River Voice, 2016, (03): 122-123.

[4] Gao Sha. Non-material cultural heritage of the northern Shaanxi Yangge protection and development[J]. Popular arts, 2015, (18): 48.

[5] Lei Juanjuan.On the basis of cultural heritage protection of northern Shaanxi Yangge cultural information protection system [J]. Electronic Testing, 2014, (23): 148-149.

[6] Ji Zhongyang. Northern Shaanxi Yangge encounter a hundred years and the modern fate of folk art [J]. Art 100, (2014) (01): 191-195. 